\title{
Estratégias didáticas para o avanço dos processos de ensino e de aprendizagem durante a Pandemia da COVID-19
}

\author{
Didactic strategies for the advancement of teaching and learning processes during the COVID-19 \\ Pandemic
}

Estrategias didácticas para el avance de los procesos de enseñanza y aprendizaje durante la Pandemia COVID-19

Thaís Petizero Dionízio

ORCID: https://orcid.org/ 0000-0002-8870-0145 Colégio Estadual Raymundo Corrêa, Brasil E-mail: thais_dionizio@yahoo.com.br

Lucas Soares de Paiva

ORCID: https://orcid.org/ 0000-0002-5146-0571

Colégio Estadual Raymundo Corrêa, Brasil E-mail: lucassdepaiva16@gmail.com

\begin{abstract}
Resumo
No atual cenário de pandemia pelo qual o mundo está passando, fez-se necessário um isolamento social para desacelerar a disseminação do novo coronavírus. Para que não haja prejuízos ao ano letivo, a Secretaria de Estado de Educação do Rio de Janeiro firmou uma parceria com o Google para que, por meio da plataforma Classroom, os professores e alunos possam dar andamento ao processo de ensino-aprendizagem. Baseado nesta iniciativa, este trabalho aborda uma pesquisa de opinião com alunos de uma escola estadual de Queimados, buscando conhecer sua realidade acerca de manipulação e disponibilidade de conexão com Tecnologias Digitais de Informação e Comunicação. Além disto, buscou-se fazer um levantamento de ferramentas didáticas possíveis de auxiliar professores e alunos na modalidade de ensino remoto, inédita para a maioria dos estudantes. Os resultados da pesquisa feita com os alunos foram compilados em gráficos e indicam que a maioria deles consegue acessar à internet de casa e possuem ao menos um smartphone para realizar o acesso à plataforma. Já as ferramentas que podem ser utilizadas norteiam de materiais mais simples, como a postagem de textos na plataforma, até o uso de aplicativos que servem de auxílio ao processo de ensino-aprendizagem. Estas ferramentas serão listadas e divulgadas aos professores da escola na intenção de lhes proporcionar um leque de opções educativas que contribuam para montagem e organização de estratégias didáticas, afim de tornar o aprendizado mais eficaz, lúdico e/ou atrativo.
\end{abstract}

Palavras-chave: Ensino-aprendizagem; Ferramentas didáticas; Pandemia; Ensino remoto; Tecnologias da informação e comunicação.

\begin{abstract}
In the current pandemic scenario that the world is going through, social isolation was necessary to slow the spread of the new coronavirus. So that there is no damage to the school year, the State Department of Education of Rio de Janeiro has signed a partnership with Google so that, through the Classroom platform, teachers and students can proceed with the teaching-learning process. Based on this initiative, this work addresses an opinion poll with students from a state school in Queimados, seeking to know their reality about the manipulation and availability of connection with Digital Information and Communication Technologies. In addition, we sought to survey possible teaching tools to assist teachers and students in the remote teaching modality, unprecedented for most students. The results of the research carried out with the students were compiled in graphs and indicate that most of them can access the internet from home and have at least one smartphone to access the platform. The tools that can be used, on the other hand, use simpler materials, such as posting texts on the platform, to the use of applications that help the teaching-learning process. These tools will be listed and disseminated to school teachers with the intention of providing them with a range of educational options that contribute to the setting up and organization of teaching strategies, in order to make learning more effective, playful and / or attractive.
\end{abstract}

Keywords: Teaching-learning; Teaching tools; Pandemic; Remote teaching; Information and communication technologies. 


\section{Resumen}

En el actual escenario pandémico por el que atraviesa el mundo, el aislamiento social era necesario para frenar la propagación del nuevo coronavirus. Para que no haya daño al año escolar, el Departamento de Educación del Estado de Río de Janeiro firmó una alianza con Google para que, a través de la plataforma Classroom, docentes y alumnos puedan proceder con el proceso de enseñanza-aprendizaje. A partir de esta iniciativa, este trabajo aborda una encuesta de opinión con alumnos de una escuela pública de Queimados, buscando conocer su realidad sobre la manipulación y disponibilidad de conexión con las Tecnologías de la Información y la Comunicación Digitales. Además, se buscó relevar posibles herramientas didácticas para asistir a profesores y estudiantes en la modalidad de enseñanza remota, inédita para la mayoría de los estudiantes. Los resultados de la investigación realizada con los estudiantes fueron recopilados en gráficos e indican que la mayoría de ellos puede acceder a internet desde casa y tener al menos un teléfono inteligente para acceder a la plataforma. Las herramientas que se pueden utilizar, en cambio, utilizan materiales más sencillos, como la publicación de textos en la plataforma, hasta el uso de aplicaciones que ayuden al proceso de enseñanza-aprendizaje. Estas herramientas serán enumeradas y difundidas a los profesores de escuela con la intención de brindarles un abanico de opciones educativas que contribuyan a la puesta en marcha y organización de estrategias de enseñanza, con el fin de hacer el aprendizaje más efectivo, lúdico y / o atractivo.

Palabras clave: Enseñanza-aprendizaje; Herramientas de enseñanza; Pandemia; Enseñanza remota; Tecnologías de la información y la comunicación.

\section{Introdução}

A Pandemia gerada pelo novo Coronavírus teve início no Brasil em 26 de fevereiro de 2020, de acordo com o Ministério da Saúde (2020). Desde então, a transmissão comunitária começou a ser confirmada em outras partes do país, afetando vários setores, como economia, saúde e educação. Em 17 de março, o governador do Rio de Janeiro publicou um decreto ( $\mathrm{N}^{\mathrm{o}} 46.973$ de 16 de março de 2020) reconhecendo a situação de emergência na saúde pública do Estado e suspendendo diversas atividades, dentre elas as aulas (Rio de Janeiro, 2020). As escolas das redes pública e privadas de ensino, além de creches e instituições de ensino superior foram fechadas para evitar a disseminação do vírus. Logo em seguida, no dia 18 de março, o Ministério da Educação publicou no Diário Oficial da União a PORTARIA No 343, de 17 de março de 2020 , que dispõe sobre a substituição das aulas presenciais por aulas em meios digitais enquanto durar a situação de pandemia do Novo Coronavírus - COVID-19 (Brasil, 2020).

De acordo com Behar (2020), a situação emergencial atual levou muitas instituições a migrarem do ensino presencial para o remoto, devido ao distanciamento geográfico entre professores e alunos que, de acordo com o decreto, ficaram impossibilitados de frequentar os espaços físicos das instituições para evitar a disseminação do vírus.

Baseado nisto, a Secretaria de Estado de Educação do Rio de Janeiro (SEEDUC-RJ) adiantou o recesso de 15 dias, que se tem em julho, para o final de março. Diante do grande desafio de ter escolas fechadas enquanto durar a pandemia, a SEEDUC-RJ teve a missão de encontrar uma solução para que o ano letivo de seus milhares de alunos não fosse prejudicado. Por meio de articulação com o Google, a Secretaria conseguiu promover a continuação das aulas através da plataforma Classroom.

O Google Classroom (ou Google Sala de Aula) é uma plataforma gratuita que permite a interação entre professores e alunos através de vários recursos e pode ser utilizada para a Educação à Distância ou, até mesmo, auxiliar aulas presenciais. O fato de não necessitar de instalação local, poder ser encontrada online e ser integrada a diversas ferramentas disponibilizadas pelo Google (Gmail, Google Drive, Google Docs, Google Forms e Google Meet) são fatores relevantes e que facilitam todo o processo de comunicação e acessibilidade (Souza \& Souza, 2016).

A plataforma cria e mantém turmas no ambiente virtual e conta com diversos recursos para a comunicação, como lançamento de comunicados na página inicial (mural), criação e envio de avaliações e trabalhos para a turma com descrições e definições de data e hora para entrega, com a opção de determinar pontuações e incluí-las em tópicos (Schiehl \& Gasparini, 2016). Além disso, é possível incluir links externos, vídeos do YouTube e até anexos do Google Drive e podem ser enviadas a mais de uma turma em uma única postagem, facilitando o trabalho do professor. Para o aluno, as tarefas deixadas possuem um 
botão de envio de arquivo, que o mesmo usará para entregar o trabalho digitado ou anexado. Feito isso, o professor pode responder ao envio dos trabalhos e avaliações realizadas pelos alunos por meio de mensagens que são direcionadas de maneira individual, facilitando o envio de feedback a respeito do que é produzido. Os professores e alunos podem desenhar, destacar e escrever anotações em documentos e arquivos em PDF (Portable Document File). Os professores podem postar trabalhos e avisos para alunos específicos em uma turma e alunos podem enviar mensagens ao professor, com cópias por e-mail. Pode-se criar rascunhos de avisos, atividades e perguntas ou programar a postagem desses itens para uma data específica. O Google disponibiliza também ferramentas como a agenda e a atualiza com os trabalhos a serem entregues e suas datas limite. É possível atribuir notas temporárias para compartilhar com os alunos posteriormente ou devolver os trabalhos com nota para todos os alunos com apenas um clique.

Através do Google Forms, já integrado à plataforma, pode-se facilmente montar questionários para revisão de estudos ou avaliação, deixando feedbacks de respostas de forma automática para o aluno. Os questionários são corrigidos automaticamente e, se as questões possuírem valor atribuído, a nota já aparece somada e indicada na tela. Posteriormente, pode ser enviada à plataforma Classroom e direcionada aos alunos através da opção "importar notas". Existe uma listagem com as notas de todos os alunos de todas as atividades pontuadas para facilitar o somatório e verificação da nota final de cada aluno (aba "Notas"). Outra ferramenta útil é o Google Meet, que permite videoconferências de forma segura e confiável, sendo possível até compartilhar tela. Os alunos convidados podem acessar a reunião (aula, debates, trabalho em grupo) pelo computador sem a necessidade de instalação de software. Já em dispositivos móveis, podem participar utilizando o App Google Meet.

Com a plataforma disponível, o grande desafio então foi aprender a manipular a plataforma e mediar as aulas através de recursos didáticos digitais. A SEEDUC-RJ disponibilizou o "Guia para Educadores", um site que fornece informações básicas para os primeiros acessos às contas do Google for Education e os acessos às salas do Google, disponibilizando orientações e uma formação online. De igual modo, a Secretaria também disponibilizou tutoriais para os gestores das unidades escolares e para os alunos.

Logo na $1^{\text {a }}$ semana de abril a plataforma Classroom já estava com escolas e turmas cadastradas (Figura 1) e os professores e alunos já puderam fazer o login e iniciar a comunicação.

Figura 1. Exemplo de Tela de Atividades da Plataforma Google Classroom.

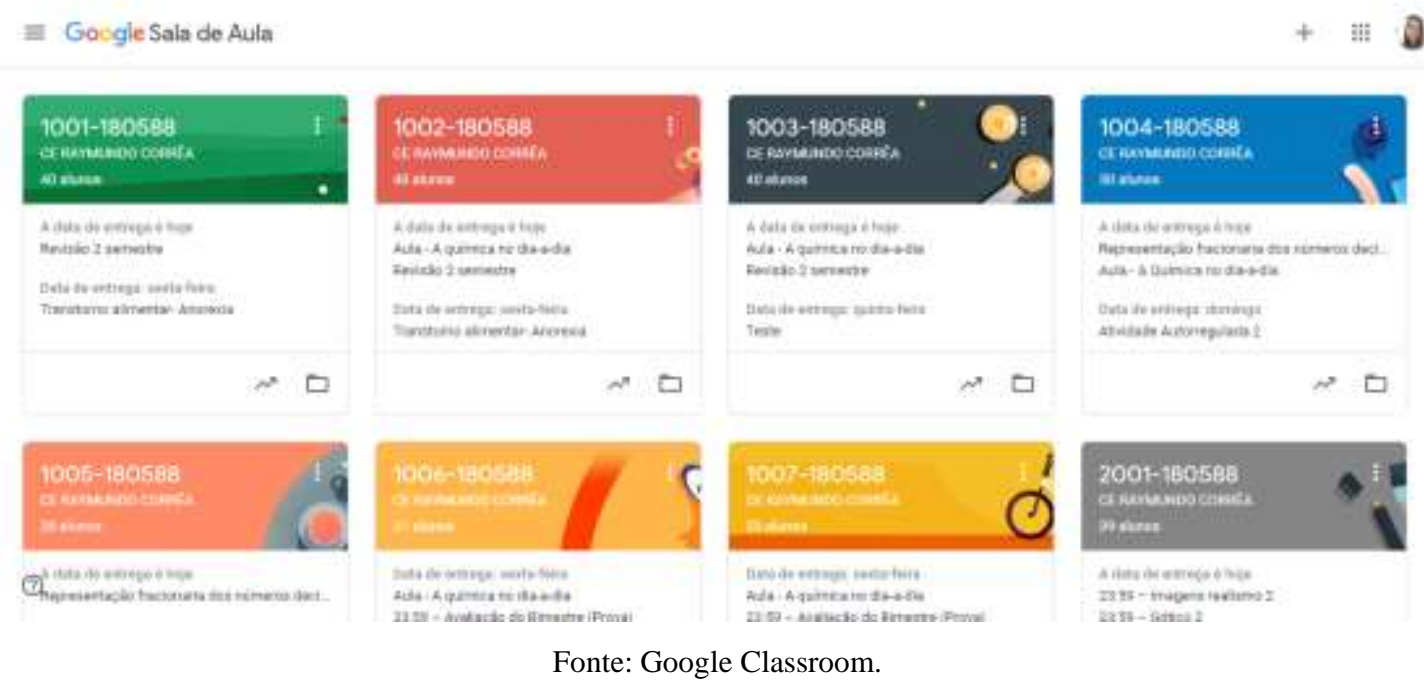

Na Figura 1 pode-se observar um exemplo de sala de aula de um professor, com suas turmas cadastradas. Em cada turma é possível observar as tarefas que devem ser entregues pelos alunos com suas respectivas datas limite de entrega. 
Além da plataforma, que já possui alguns recursos implementados, o professor pode fazer o uso das Tecnologias da Informação e Comunicação (TIC) como ferramentas didáticas de apoio à aprendizagem. A exemplo, pode-se citar vídeoaulas, jogos virtuais e aplicativos, que já têm apresentado eficiência (Coll, 2014; Freitas, 2014; Rigo, 2014; Dionizio et al., 2019). As TIC podem desenvolver a capacidade de observação do aluno e ilustrar situações mais abstratas, contribuindo de forma significativa para o processo de aquisição do conhecimento (Souza \& Souza, 2016; Santos, 2020).

Levando em consideração esta mudança no ensino adotada durante o período de isolamento social, este trabalho buscou conhecer a realidade dos alunos de uma escola estadual localizada no município de Queimados (RJ) quanto a disponibilidade de acesso ao ensino remoto e, também, pesquisar ferramentas didáticas possíveis de serem utilizadas em paralelo com a plataforma. Assim o professor pode montar uma estratégia didática, coordenando um conjunto de atividades/ferramentas, para promover um aprendizado mais interativo e lúdico.

\section{Metodologia}

Segundo Gil (2002), as pesquisas de levantamento (opinião) são caracterizadas por fazer interrogações diretas a determinadas pessoas, a fim de investigar e conhecer seus comportamentos, solicitando-as informações sobre o problema estudado e obtendo-se conclusões através dos dados coletados. De acordo com Malhotra (2006), o processo de pesquisa pode ser dividido em seis etapas: i) definição do problema, etapa em que deverá levar-se em conta a finalidade do estudo e suas informações mais relevantes; ii) desenvolvimento de uma abordagem, em que deve-se buscar informações que sirvam como base teórica, estruturando a pesquisa; iii) a formulação da concepção da pesquisa, etapa que determina como obter as informações necessárias, onde se cria um instrumento de coleta de dados; iv) o trabalho de campo, onde se dará aplicação de questionários ou entrevistas pessoais; v) preparação e análise de dados, etapa de editoração, codificação, transcrição e verificação dos dados; vi) preparação e apresentação de relatório, etapa final para documentação por escrito ou apresentação verbal dos resultados, utilizando gráficos e tabelas para facilitar a demonstração. Estas etapas podem ser adaptadas de acordo com a necessidade de cada pesquisador.

Inicialmente, buscou-se verificar a real situação de alunos da rede estadual de ensino mediante a estratégia adotada pela SEEDUC-RJ. Neste sentido, a pesquisa foi aplicada a estudantes de 15 turmas do Colégio Estadual Raymundo Corrêa, localizado no município de Queimados - RJ. Devido ao isolamento social, este mapeamento foi realizado através de um questionário aplicado pelo Google Forms disponibilizado através da plataforma Classroom na $1^{\text {a }}$ semana de acesso e, também, enviada pelos grupos das turmas formados por WhatsApp na tentativa de alcançar os alunos que ainda não tinham conseguido acessar a plataforma. O questionário virtual composto por 19 questões ficou disponível durante todo o mês de abril tendo como público-alvo 512 alunos, divididos em 7 turmas de $1^{\circ}$ ano, 4 de $2^{\circ}$ ano e 4 de $3^{\circ}$ ano. Buscou-se averiguar se os alunos possuíam aparelhos para acessar a plataforma e alguma conexão disponível, seja por banda larga ou dados móveis; e conhecer a opinião dos estudantes sobre o ensino remoto e suas expectativas para iniciar esta nova fase. Com os dados tabelados, gráficos foram criados a fim de discutir os resultados da pesquisa.

Em um segundo momento, foi realizado um levantamento de TIC que professores e alunos podem utilizar, em conjunto com a plataforma, para auxiliar este novo processo de ensino-aprendizagem adotado pela SEEDUC-RJ. Para tal, foi feita uma pesquisa documental na internet (site Google) e também no Play Store na busca por ferramentas didáticas que atendam a diversas disciplinas, se aliem ao ensino remoto, sejam gratuitas, de fácil acesso e manipulação, que tenham ou não relatos de experiência. De acordo com Gil (2002), pesquisas documentais assemelham-se às bibliográficas, diferenciando-se apenas na natureza das fontes. Enquanto a pesquisa bibliográfica faz uso das contribuições de vários autores sobre determinado assunto, constituindo-se sobretudo por material impresso localizado nas bibliotecas, a pesquisa documental vale-se de materiais que podem ser reelaborados de acordo com os objetos da pesquisa, por meio de fontes mais diversificadas e 
dispersas.

\section{Resultados e Discussão}

\subsection{Pesquisa social}

Ao total, foram obtidas 436 respostas, correspondendo a cerca de $85 \%$ dos alunos alvo da pesquisa. Portanto, $15 \%$ deles não enviaram suas respostas, motivo pelo qual algumas hipóteses foram levantadas: i) possuem internet mas não acessaram durante o tempo em que o questionário estava disponível, ii) não quiseram fazer parte da pesquisa ou iii) não possuem acesso à internet e, portanto, não ficaram sabendo da pesquisa. A escola já vem mapeando estes alunos afim de, se possível, direcioná-los à plataforma. Medidas estão sendo tomadas para sanar a deficiência de acesso às aulas de alguns dos alunos. A SEEDUC já está sendo informada acerca daqueles que não possuem acesso para que chip de operadores de telefonia e/ou materiais impressos possam ser enviados.

Na Figura 2 é possível conferir, por meio de gráficos, as respostas das 5 primeiras perguntas do questionário na tentativa de caracterizar os alunos respondentes.

Figura 2. Gráficos das respostas às perguntas de 1 a 5 do questionário.

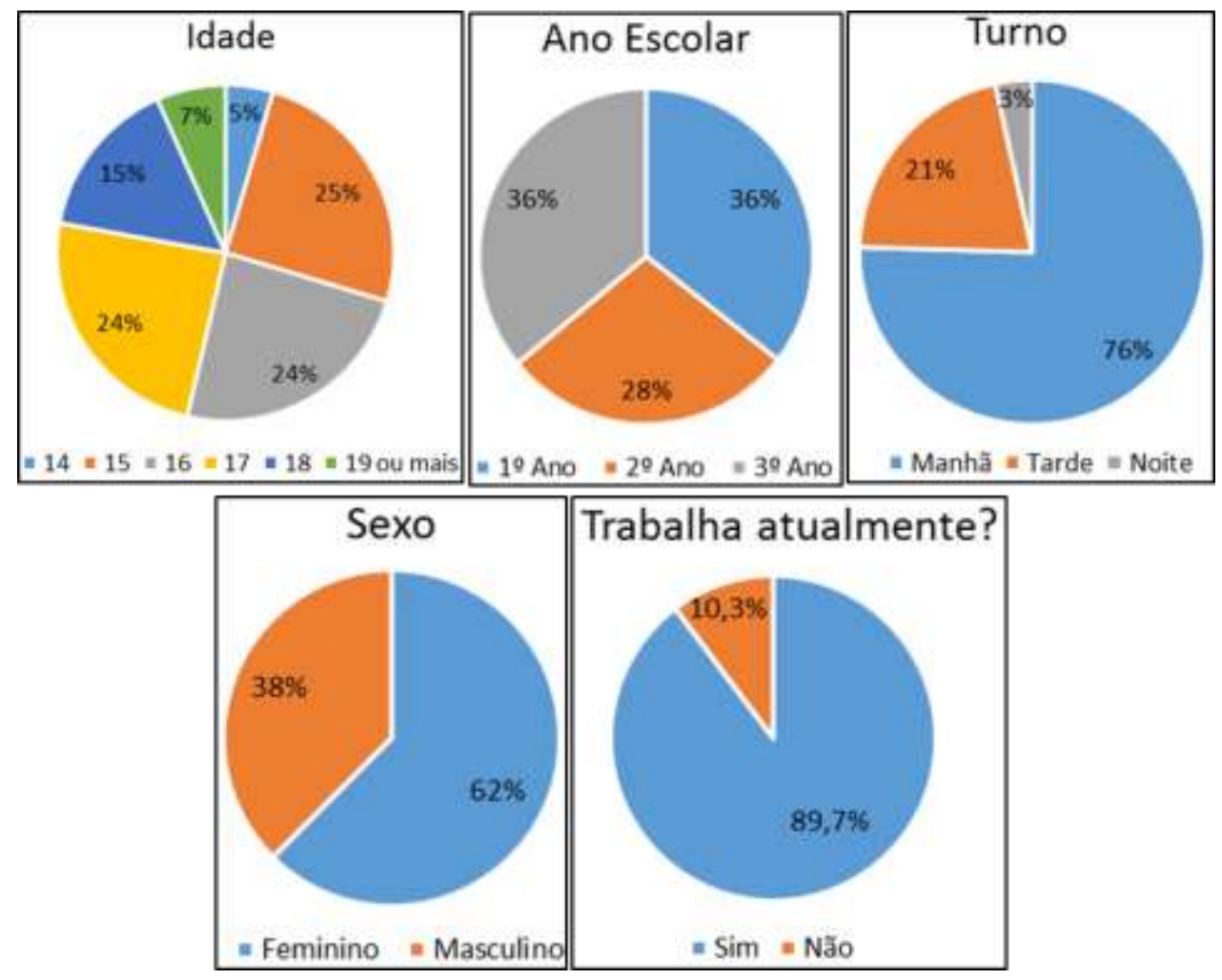

Fonte: Autores (2020)

De acordo com a Figura 2, nota-se que dos alunos respondentes, a grande maioria (78\%) está na faixa etária compreendida entre 14 e 17 anos e os demais (22\%) possuem ou estão acima da maioridade. Apenas $3 \%$ dos alunos estudam à noite, o que justifica a grande porcentagem na faixa etária da adolescência vista anteriormente, $21 \%$ estudam à tarde e $76 \%$ pertencem ao turno matutino. Cerca de $36 \%$ dos alunos estudam no $1^{\circ}$ ano do Ensino Médio, $28 \%$ pertencem ao $2^{\circ}$ ano e $36 \%$ ao $3^{\circ}$ ano. Sabendo que quase metade dos alunos alvo eram de $1^{\circ}$ ano, nota-se que cerca de $30 \%$ deles não responderam ao questionário e, um olhar mais criterioso às respostas nos permite identificar a maioria como sendo pertencente ao turno da noite. Cerca de $38 \%$ pertence ao público masculino enquanto $62 \%$ são do feminino. Dos que trabalham atualmente, somam-se 
10,3\% do total, enquanto $89,7 \%$ declararam não trabalhar.

Na Figura 3, constam os gráficos referentes as respostas das questões 6 a 9 que versam sobre o acesso à plataforma.

Figura 3. Gráficos das respostas às perguntas de 6 a 9 do questionário.

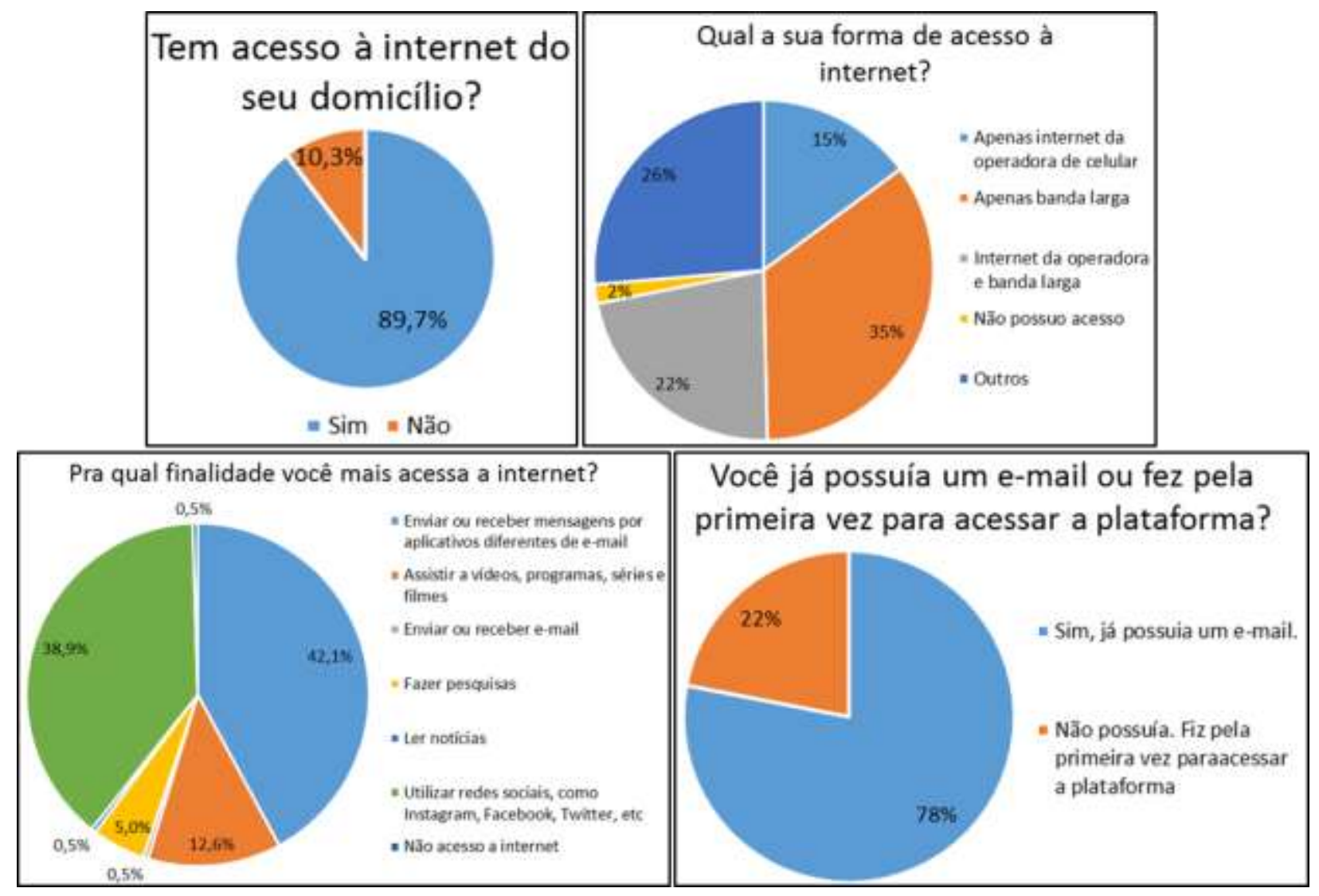

Fonte: Autores (2020)

Analisando os gráficos da Figura 3 sobre acessibilidade, nota-se que cerca de 90\% dos alunos declaram possuir acesso à internet do próprio domicílio, enquanto uma minoria (10\%) declara não ter acesso de casa. Quando perguntados sobre a forma de acesso, $15 \%$ declararam acessar apenas pelos dados móveis da operadora de telefonia, 35\% declaram possuir apenas banda larga e $22 \%$ tem estas duas opções. Cerca de $2 \%$ declararam não possuir acesso, embora o tenham respondido, e $26 \%$ disseram ter acesso por outros meios, dos quais não foram questionados. Quando questionados sobre a finalidade de acesso, quase metade dos alunos (42\%) disseram acessar para enviar e receber mensagens por aplicativos diferentes de e-mail, como por exemplo o WhatsApp, Messenger e Telegram; cerca de 39\% tem por finalidade acessar redes sociais, como por exemplo o Facebook, Instagram e Twitter; 12,6\% tem por objetivo maior assistir vídeos, programas, filmes e séries; $5 \%$ tem pesquisas em geral como finalidade maior; cerca de $0,5 \%$ utiliza para enviar e-mail; e $0,5 \%$ declarou não acessar. Sobre possuir conta de email, $22 \%$ declaram já possuir e $78 \%$ disseram que fizeram pela primeira vez para acessar a plataforma.

Perguntas de opinião foram lançadas (questões de 10 a 19) para saber o que os alunos achavam de estudar a distância. A Figura 4 mostra os gráficos das respostas referentes às questões 10 a 13. 
Figura 4. Gráficos das respostas às perguntas de 10 a 13 do questionário.

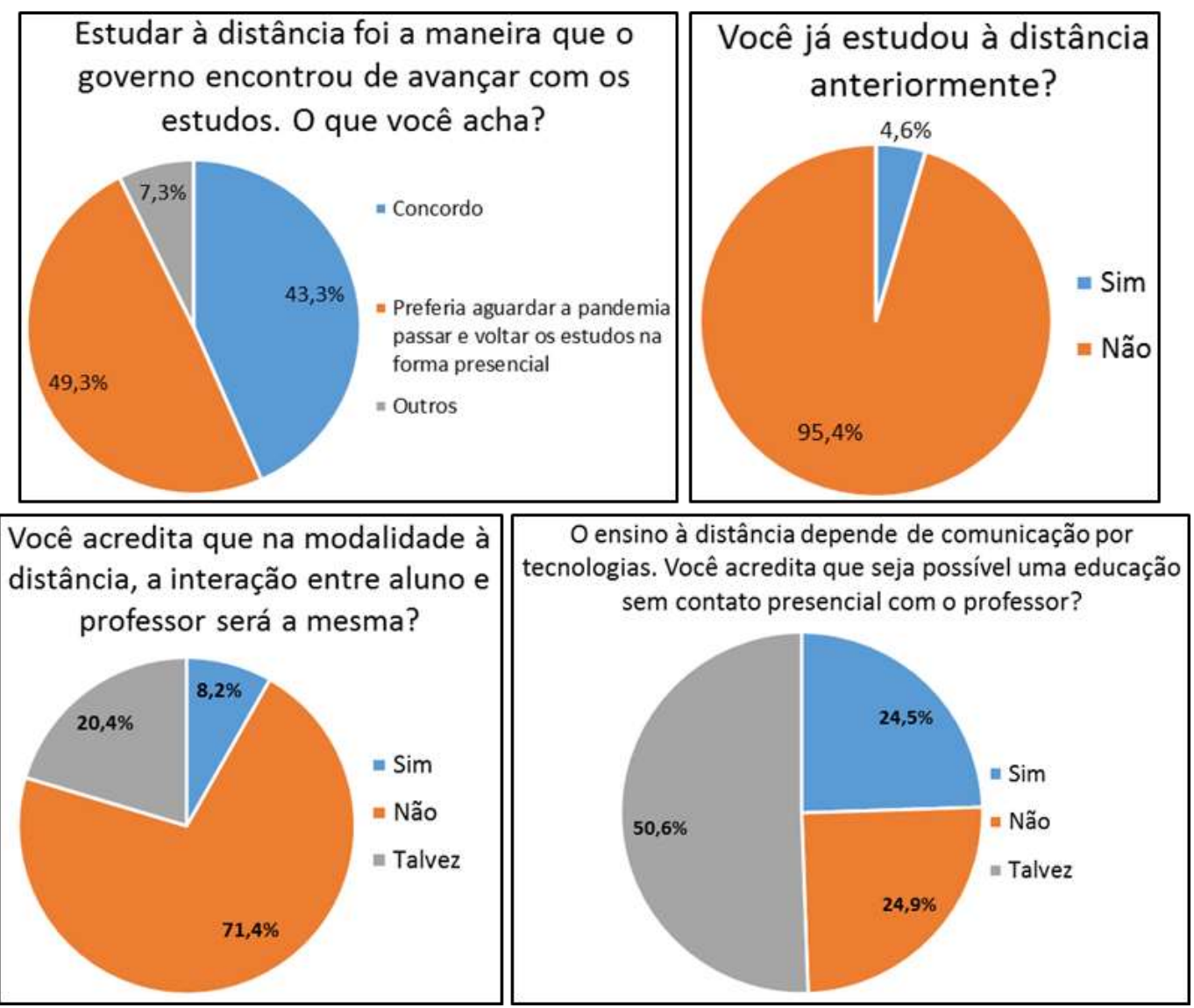

Fonte: Autores (2020)

Na Figura 4 constam os gráficos referente às perguntas de 10 a 13, que buscou conhecer a opinião deles sobre a educação remota. Pode-se verificar que cerca da metade dos alunos $(49,3 \%)$ disse preferir aguardar a pandemia passar e voltar aos estudos de forma presencial, enquanto que, quase a outra metade, 43,3\% concordou com a atitude do governo de tentar avançar com os estudos de maneira remota. Apenas 7,3\% dos entrevistados marcaram a alternativa "outro", dos quais mostraram-se favoráveis à atitude do governo mas temeram por aqueles que não têm condições de acessar ou temeram não conseguir acompanhar as atividades por dificuldades na leitura e interpretação, levando-os a algum prejuízo. Quando foram indagados se já estudaram à distância anteriormente, cerca de 5\% disseram já ter tido esta experiência, enquanto que, aproximadamente, 95\% dos alunos nunca tiveram contato com a EaD antes. Quando foram perguntados se acreditavam que a interação aluno-professor seria a mesma, apenas 8,2\% disseram que sim, 20,4\% disseram que talvez, e 71,4\% não acreditam. Quando perguntados se achavam possível uma educação sem o contato presencial com o professor, metade deles (cerca de $50 \%$ ) responderam que talvez, enquanto que $1 / 4$ dos alunos (cerca de $25 \%$ ) disseram que sim e os outro 1/4 não acham possível, uma reação já esperada devido a figura do professor, de modo presencial, ter feito parte da rotina deles até então.

As respostas das questões 14 a 17 estão plotadas e apresentadas na Figura 5, a seguir. 
Figura 5. Gráficos das respostas às perguntas de 14 a 17 do questionário.
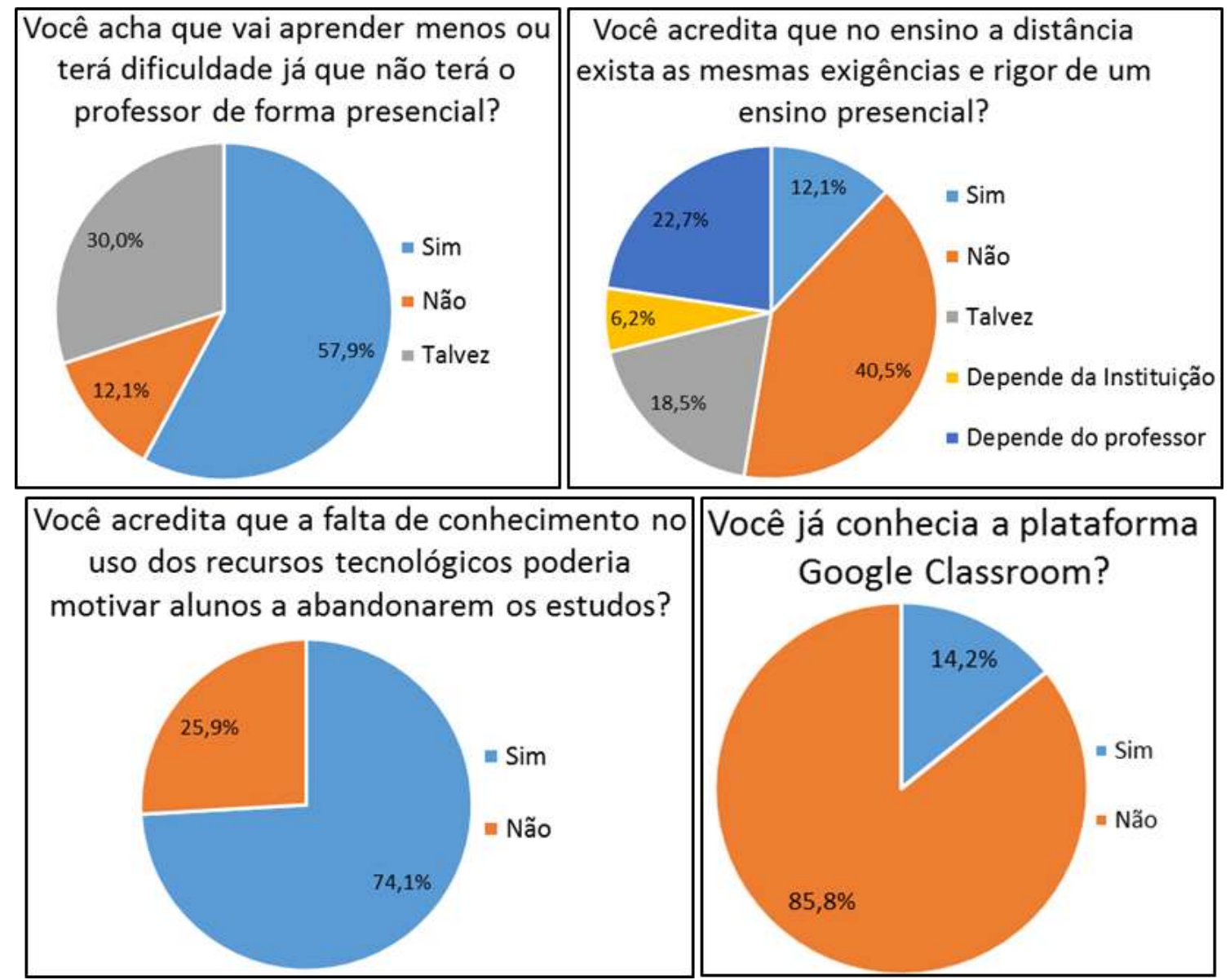

Fonte: Autores (2020)

Na Figura 5, ao continuar as perguntas de opinião, foram obtidos os seguintes resultados: ao serem questionados se achavam que iriam aprender menos ou que teriam dificuldade por não ter o professor presencialmente, cerca de $60 \%$ disseram que sim, 30\% responderam que talvez e 12\% acreditam que não; quanto a acharem que no ensino à distância as exigências e rigor são os mesmos de um ensino presencial, a grande maioria, cerca de $40 \%$, acredita que não, seguidos de $22,7 \%$ que acreditam depender do professor, 18,5\% disseram que talvez, 12,1\% disseram que sim e a minoria $(6,2 \%)$ acredita depender da Instituição; acerca da evasão escolar, perguntou-se se eles acreditavam que a falta de conhecimento no uso de recursos tecnológicos poderia motivá-los a abandonarem os estudos, $74,1 \%$ acreditam que sim, enquanto que $25,9 \%$ acreditam não ser este um motivo para evasão; ao serem perguntados se já conheciam a plataforma Classroom, incríveis 14,2\% disseram que sim, mas para a grande maioria, $85,8 \%$, é uma novidade, conforme o esperado.

Para finalizar a pesquisa de opinião, as perguntas 18 e 19 buscaram averiguar os equipamentos disponíveis pelos alunos para fazer o acesso à plataforma e conhecer suas expectativas quanto ao início do ensino remoto. Essas respostas foram plotadas em gráficos que estão dispostos na Figura 6. 
Figura 6. Gráficos das respostas às perguntas de 18 e 19 do questionário.

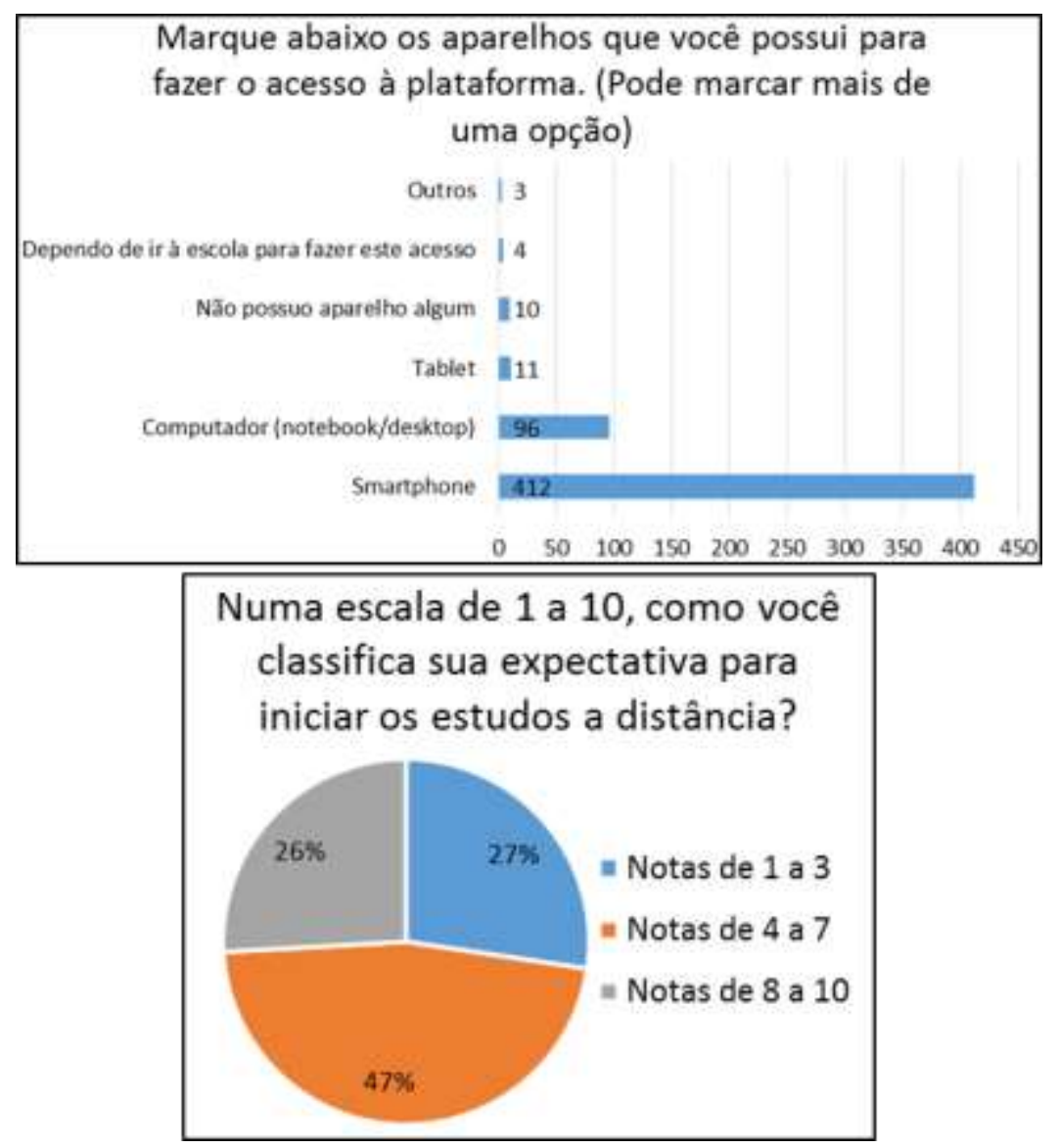

Fonte: Autores (2020)

Na Figura 6, é possível observar as respostas às duas últimas questões que foram lançadas aos alunos. A primeira delas era para marcarem, dentre uma lista fornecida, os aparelhos que eles possuem disponíveis para realizar o acesso à plataforma. Cerca de $95 \%$ dos alunos declararam ter smartphone disponível para acessar a plataforma, 22\% dispõem de computador, 2,5\% possuem tablet, 2,5\% declararam não possuir aparelho para acesso, $1 \%$ declarou necessitar ir à escola fazer este acesso e $1 \%$ marcou outros aparelhos. No momento da pesquisa a SEEDUC-RJ cogitava abrir as escolas para alunos sem acessibilidade, para que utilizassem os computadores da escola, por este motivo tinha a opção "Dependo de ir à escola para fazer o acesso". Contudo, esta possibilidade não foi adiante. Por fim, foi pedido que escolhessem um número, em uma escala de 1 e 10, para classificar suas expectativas quanto ao início no ensino à distância. Como resposta, a grande maioria (47\%) mostrou ter uma expectativa mediana e deram notas variando entre 4 e 7; 27\% deram notas menores (entre 1 e 3 ) indicando uma baixa expectativa; e outros $26 \%$ mostraram-se mais positivos e animados e deram notas variando entre 8 e 10 .

Ao analisar estes resultados fica claro que a maioria dos alunos possui condição de acessar a plataforma, ainda que por um smartphone. Não é o ideal, mas como o ensino remoto é uma medida provisória durante a pandemia, o smartphone servirá de apoio enquanto não se pode voltar às atividades presenciais. A grande maioria teme um aprendizado ineficaz por não ter um professor mediando seus estudos de maneira presencial. A insegurança neste momento é totalmente compreensível, pois estudar remotamente é uma metodologia inédita para a maioria dos alunos. Todavia, a maior preocupação gira em torno da minoria ainda sem acesso. 


\subsection{Ferramentas didáticas}

O levantamento realizado permitiu conhecer diversas ferramentas que podem ser facilmente indicadas ou mediadas pelos professores, mas é importante que haja planejamento e que se faça um diagnóstico da turma, pois conhecendo-se a necessidade do público-alvo obtém-se êxito no emprego da atividade (Dionizio et al., 2019). As ferramentas analisadas por este trabalho foram videoaulas, aplicativos, sites educacionais, filmes e memes e encontram-se discutidas a seguir.

Acerca das vídeoaulas, houve um crescimento na sua utilização como ferramenta didática (Negromonte \& Silva, 2018; Oliveira \& Stadler, 2014) e, plataformas de vídeo como o YouTube, têm facilitado essas publicações. Ao realizar uma pesquisa nesta plataforma, foi obtido facilmente o acesso a vídeoaulas de diversas disciplinas e assuntos ministrados a nível médio, que variam desde abordagens mais básicas até aulas de preparação para o vestibular. Muitos professores e instituições particulares e públicas disponibilizam seus vídeos na intenção de ensinar e/ou reforçar conteúdos já abordados nas disciplinas para a promoção do ensino-aprendizagem, pois os vídeos potencializam a exposição do conteúdo. Ao realizar a busca, notou-se que a maior oferta concentra-se nas disciplinas das áreas de Ciências da Natureza e Matemática e as menos ofertadas são das áreas de Humanas e de Linguagens, como Filosofia, Sociologia, Artes e Educação Física.

Os vídeos mais visualizados e curtidos apresentam, geralmente, uma linguagem mais simples, conteúdo mais específico, de canais mais antigos e com a imagem do professor explicando o conteúdo através de slides ou uma lousa. Podemos citar como exemplo o canal de matemática do Professor Ferreto ("Ferretto Matemática"), focado em vestibular, criado em 2014 e que, até o momento da realização da busca (maio/2020), possui 171.103.031 visualizações. Neste canal os estudantes podem contar com vídeos mais curtos de resolução de questões, dicas e macetes (de 3-10 min aproximadamente) ou aulas mais completas (de até mais de 1h). O canal "Prof. Marx - Mundo da Química", existente desde 2013, possui 4.007.868 de visualizações até o momento (maio/2020), apresenta videoaulas mais curtas (variando de 2 a 22 min em sua maioria) com conteúdo muito bem explicado e/ou resolução de exercícios com uma abordagem bem dinâmica.

Existem vídeos mais focados em passar conteúdo com uma abordagem mais convencional e formal e outros com abordagem mais contextualizada e/ou lúdica, contemplando o grande público de estudantes telespectadores. Canais criados por professores, geralmente, abordam uma única disciplina. Mas canais inscritos por Instituições, públicas ou privadas, como por exemplo o "Descomplica", "Seduc-AM" e "Mediação Tecnológica Rondônia", ofertam, em sua maioria, videoaulas de diversas disciplinas (Biologia, Filosofia, Física, Geografia, História, Matemática, Português, Química, Redação, Sociologia). Esta é uma boa ferramenta para os professores utilizarem com seus alunos, pois não há necessidade do aluno fazer download, logo não dependerá da memória de armazenamento do aparelho utilizado (smartphone ou computador), facilitando o acesso.

No concernente ao uso de aplicativos, notou-se que com o crescente desenvolvimento das TIC, surgiu uma grande variedade desta ferramenta com fins educacionais, que podem auxiliar o professor em sua prática docente (Hitzschky et al., 2018). Existem aplicativos das mais diversas áreas do saber que podem ou não ser mediados pelo professor e são obtidos gratuitamente através do Play Store. Algumas disciplinas exigem grande dedicação e exercitação para que haja maior compreensão de seus termos e conteúdos, como por exemplo Língua Portuguesa e Língua Estrangeira, que possuem regras para serem seguidas. Os aplicativos "Português no Bolso" e "Gramática da língua portuguesa" contém várias dicas gramaticais e ortográficas, possuem um tamanho pequeno (menor que 3MB) e podem ser utilizados off-line. O "Duolingo" é um curso excelente para quem deseja estudar Inglês e Espanhol, gratuito, interativo e não necessita mediação. Ainda na área de Linguagens, Códigos e suas Tecnologias, podemos citar o "Google Arts \& Culture" que permite que os usuários vejam diversas coleções de arte que estão disponíveis em museus do mundo todo em imagens com alta resolução e conteúdo sobre informações importantes da obra. Para aulas de Educação Física podem ser utilizados aplicativos para guiar e exemplificar exercícios físicos como o "Nike Training Club", que oferece diversos tipos de treinos gratuitos, desde força e cardio a sessões de yoga e mobilidade, para diferentes tipos de condicionamento físico; e o "Exercícios de Alongamento" que disponibiliza 
diversos alongamentos para grupos musculares, flexibilidade e alívio de dor.

As Ciências da Natureza, que são disciplinas de cunho experimental, podem contar com aplicativos de laboratórios virtuais para incrementarem os estudos ao exemplificarem reações e esquemas lúdicos de variados assuntos. A exemplo, vale a pena citar o aplicativo "Lab. de Reações" (de Química), em que é possível conhecer as vidrarias e acompanhar roteiros já prontos de reações químicas e o "Tabela Periódica Educalabs" em que é possível ver de maneira dinâmica a tabela periódica, clicar sobre o símbolo de um elemento e conhecer suas características; o "Physic at School" (de Física) que possibilita trabalhar simulações em 3D nas áreas da mecânica, campo gravitacional, termodinâmica, entre outras e o idioma pode ser mudado para o português; e o "Órgãos Internos em 3D" (de Biologia) em que o usuário pode ter uma visão 3D do corpo humano e obter sua descrição anatômica.

Existem aplicativos mais abrangentes, como o "Formulando", dedicado aos alunos que vão prestar Enem e vestibular. Nele os estudantes contam com fórmulas e simulados na área de exatas. Há também o "RevisApp" que apresenta resumos de conteúdos de diversas disciplinas voltados para o estudo do vestibular, é gratuito e pode ser utilizado off-line.

Aplicativos na área de Ciências Humanas não são tão abundantes (em quantidade) quanto os de Ciências da Natureza e Matemática, mas é possível encontra-los também de maneira gratuita, como o StudyGe (de Geografia), em que se pode estudar mapas geográficos e participar de quizzes através de uma tela bem interativa.

Além disso, os estudantes contam com aplicativos em que se permitem fazer reuniões ("Teams") e fazer leituras e ouvir áudios de textos em pdf ("Xodo"). A Universidade Federal do Rio Grande do Sul criou uma tabela com os softwares educacionais livres para dispositivos móveis, onde listou e classificou mais de 300 aplicativos de todas as áreas e níveis do conhecimento (do Ensino Infantil ao Superior).

Como outra opção de ferramenta didática, é possível fazer o uso de sites que dispõem de arquivos e materiais para o estudo, podendo auxiliar na construção do conhecimento. Pode-se citar o "Portal Domínio Público" que é uma biblioteca digital e disponibiliza, gratuitamente, milhares de obras literárias, artísticas e científicas (na forma de textos, sons, imagens e vídeos) que constituem o patrimônio cultural brasileiro e universal, contribuindo para o desenvolvimento da educação e da cultura. É possível, também, encontrar sites de Laboratórios de Ciências, como por exemplo o "LabVirt" desenvolvido pela USP e que apresenta simulações a partir de roteiros de alunos de ensino médio de escolas da rede pública, para área de Química e Física. O site do projeto "Era Virtual", que vem sendo desenvolvido desde 2008, promove visitas virtuais a Museus, Exposições Temporárias e Patrimônios Culturais, com visualização $360^{\circ}$ dos museus brasileiros e seus acervos. O professor pode indicar ao aluno uma visita e promover uma viagem surpreendente ao patrimônio cultural brasileiro. O "CNEC NOAS" é um núcleo de computação aplicada, destinado ao desenvolvimento de objetos de aprendizagem significativa, estruturados em simulações computacionais de fenômenos. Em seu site estão disponíveis diversos simuladores de conteúdos e jogos interativos que vão da Educação Infantil ao Ensino Superior.

Existem sites mais específicos por disciplina, como o "Café com Sociologia", que conta com vários podcasts, orientações de apoio ao professor, artigos, banco de entrevistas, livros e revistas na área de Sociologia. Enquanto outros sites são mais abrangentes, como o "Blog do Prof. Warles" que, embora lecione matemática na Rede Estadual de Goiás, disponibiliza simulados e quizzes de diversas disciplinas. O Blog "Oficinas Pedagógicas de Saúde" compartilha roteiros de oficinas pedagógicas aplicadas no espaço escolar, dicas e notícias na área da saúde, em que o aluno pode se inteirar e ser motivado a ter uma melhor qualidade de vida. Até mesmo um curso Pré-vestibular, o "Conquistar", foi encontrado na internet totalmente online e gratuito, disponibilizado pela SEDUC-AM e focado em alunos do Ensino Médio da rede estadual de ensino e comunidade em geral interessada em potencializar a sua preparação para os exames de acesso ao Ensino Superior.

A utilização de filmes como complementação do estudo também tem se mostrado um bom aliado ao campo educacional. Se bem escolhida, planejada e mediada, esta ferramenta audiovisual, interativa e facilitadora age estimulando o 
interesse dos alunos pelo assunto e torna-se, inclusive, ideal ao ensino interdisciplinar, pois um único filme abrange vários assuntos. Luchetti \& Amaro (2014), utilizaram os filmes: "300", "Tróia" e "Gladiador" em turmas de $1^{\circ}$ ano de ensino médio como ferramenta na disciplina de história e relataram o quão enriquecedora foi a experiência, que permitiu aos estudantes criarem uma criticidade maior em relação ao conteúdo trabalhado, além das aulas terem ficado mais dinâmicas e atrativas. Quintino \& Ribeiro (2010) tornaram a aprendizagem de química mais significativa estimulando o interesse dos alunos com a utilização dos filmes: "O dia depois de amanhã", "O Núcleo: Missão ao centro da Terra" e "O óleo de Lorenzo" em turmas de Ensino Médio, abordando assuntos de química geral, orgânica e meio ambiente.

Filmes como "Treinador Carter" e "Carruagens de fogo" podem ser utilizados para trabalhar valores com os alunos, ensinando-os postura e respeito (Oliveira \& Sugayama, 2014); ainda neste sentido, "Murderball - paixão e glória" traz a temática de deficiência física e a superação através do esporte, ao abordar sobre equipes esportivas que participaram da Paraolimpíada de Atenas, superando obstáculos e limitações físicas. O filme "Matrix", que evidencia a importância da consciência, valorizando o conhecimento e emoções, utilizando símbolos e mitologia, pode ser utilizado em filosofia e sociologia. Em suma, há uma variedade de filmes possíveis de serem utilizados para fins educacionais, podendo ser relacionados a uma disciplina específica ou abordar assuntos interdisciplinares, tratar conteúdos específicos ou trabalhar motivação, ética, valores e princípios, por exemplo.

O meme, última ferramenta aqui abordada, é um gênero textual que abarca tanto a linguagem verbal quanto a nãoverbal e vem sendo veiculado nas redes sociais de forma rápida e recorrente, com teor humorístico. Esta ferramenta pode aliarse ao ensino ao despertar o interesse dos alunos sobre temas e/ou notícias atuais. Abreu (2018), professora de História da SEEDUC-RJ, desenvolveu a pesquisa: "A África através dos memes: Perspectivas para uma escrita de aula" em que fez o uso de memes nas suas aulas de história, levando os alunos a desenvolverem senso crítico e promovendo o aprendizado de aspectos históricos, além disso criou a página “@memes_na_historia” no Instagram para divulgação da temática e trabalhos desenvolvidos.

É possível propor a criação ou analisar memes já existentes que envolvam a temática estudada a fim de compreender fatos de maneira mais interativa e lúdica. Pereira \& Nascimento (2017), utilizaram memes oriundos da página humorística "Bode Gaiato", que apresenta memes numa linguagem nordestinizada, em aulas de Língua Portuguesa propondo uma adequação à linguagem padrão, o que permitiu uma maior habilidade leitora e capacidade de reescrita seguindo as normas da linguagem, além de trazer a conhecimento os valores socioculturais e regionais do Nordeste. Já Silva (2019) aplicou uma metodologia diferenciada para o ensino de geografia, propondo aos alunos a criação de memes a partir de fotos e imagens dos bairros onde moram, trazendo momentos de reflexão e criatividade. $\mathrm{O}$ meme, por ser apenas uma imagem, é mais prático para os alunos e não ocupa muito espaço de memória em seus aparelhos (smartphone ou computador), além de chamar mais atenção pela ilustração, ser divertido e promover o aprendizado e o senso crítico.

\section{Considerações Finais}

Durante a realização deste trabalho foi possível averiguar a opinião dos alunos, conhecer sua realidade quanto o acesso à plataforma e, também, suas expectativas para o ensino remoto, além disso, foi possível fazer um levantamento das TIC disponíveis na internet para que os professores das mais diversas disciplinas possam fazer o uso em conjunto com a plataforma a fim de facilitar a aprendizagem dos alunos.

A pesquisa de opinião realizada na $1^{\mathrm{a}}$ etapa deste trabalho permitiu averiguar que 9 a cada 10 alunos respondentes possuem acesso à internet do próprio domicílio. Praticamente a metade dos alunos mostrou-se de acordo com as aulas à distância para dar seguimento aos estudos, embora alguns temeram a dificuldade na compreensão dos conteúdos por não ter um professor intermediando o processo de maneira presencial. Cerca de 95\% dos alunos disponibilizam ao menos um 
smartphone para acessar a plataforma. Levando-se em conta o feedback positivo dos alunos e que a plataforma pode ser facilmente manipulada, esta alternativa de continuar os estudos remotamente é eficaz para quem consegue acessa-la.

Ademais, os professores podem contar com diversas videoaulas, aplicativos, sites, filmes e memes para os mais variados níveis de ensino e assuntos. O uso das tecnologias digitais gratuitas podem fortalecer as ações pedagógicas, gerar maior motivação e interação entre aluno-professor e aluno-aluno e facilitar a aprendizagem. Se bem organizada e planejada, a utilização destas ferramentas neste momento de Pandemia, em que a educação só avança se for remotamente, mostram-se grandes estratégias didáticas à prática educacional. As atividades aqui pesquisadas serão listadas e disponibilizadas aos professores da escola na intenção de proporcionar um maior conhecimento sobre os recursos existentes. Apropriar-se destas ferramentas tecnológicas é um desafio mas a sua utilização é uma forma de promover o conhecimento e se aproximar do aluno.

A facilidade e a abrangência com as quais se podem encontrar atividades diferenciadas na internet só aumenta a certeza de que a Educação está passando por grandes mudanças e a Pandemia está catalisando este processo. É certo de que quando tudo isso acabar, muitos professores irão voltar à metodologia anterior (convencional) mas espera-se que a grande maioria esteja aberta a tornar assíduo o uso de ferramentas digitais educacionais em suas aulas. Novos tempos, novas estratégias!

\section{Referências}

Abreu, C. B. (2018). A África através dos memes: perspectivas para uma escrita de aula. Monografia de Especialização. Universidade Federal do Rio De Janeiro, Rio de Janeiro.

Behar, P. A. (2020). O Ensino Remoto Emergencial e a Educação a Distância. Jornal da Universidade, UFRGS. https://www.ufrgs.br/coronavirus/base/artigoo-ensino-remoto-emergencial-e-a-educacao-a-distancia/.

Brasil. (2020). PORTARIA N ${ }^{\circ}$ 343, DE 17 DE MARÇO DE 2020. Diário Oficial da União, 18 mar. 2020. https://www.in.gov.br/en/web/dou/-/portaria-n-343de-17-de-marco-de-2020-248564376.

Coll, C. (2014). Os educadores, as TIC e a nova ecologia da aprendizagem. Associação Nova Escola, ed. 272. https://novaescola.org.br/conteudo/253/educadores-tic-nova-ecologia-aprendizagem-tecnologia.

Dionízio, T. P., Silva, F. P., Dionízio, D. P., \& Carvalho, D. M. (2019). O Uso de Tecnologias da Informação e Comunicação como Ferramenta Educacional Aliada ao Ensino de Química. EaD em Foco, 9 (1), p. 1-15. https://eademfoco.cecierj.edu.br/index.php/Revista/article/view/809.

Freitas, L. F. A. (2014). As TIC no contexto escolar do ensino médio: um estudo em escolas da rede pública de Santa Maria - RS. Monografia de Especialização. Universidade Federal de Santa Maria, 24 p.

Gil, A. C. (2002). Como elaborar projetos de pesquisa. $4^{\mathrm{a}}$ Ed. São Paulo: Atlas.

Hitzschky, R. A., Arruda, J. S., Lima, C. A. Siqueira, L. M. R. C., \& Filho, J. A. C. (2018). O uso de aplicativos educacionais no Ensino Fundamental em tempos de aprendizagem móvel: contribuições para a formação de professores. Revista Tecnologias na Educação, 10 (26). https://tecedu.pro.br/wpcontent/uploads/2018/09/Art7-vol.26-EdicaoTematicaVIII-Setembro2018.pdf.

Luchetti, S. A., \& Amaro, H. S. (2014). A Utilização de Filmes nas Aulas de História. Cadernos PDE - Os Desafios da Escola Pública Paranaense na

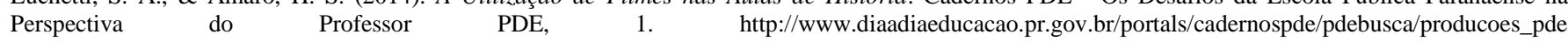
/2014/2014_uem_hist_artigo_solange_aparecida_luchetti.pdf.

Malhotra, N. (2006). Pesquisa de marketing: uma orientação aplicada. (4a ed.), Bookman.

Ministério da Saúde. (2020). Brasil confirma primeiro caso da doença. Brasília: Ministério da Saúde. https://www.saude.gov.br/noticias/agencia-saude/46435brasil-confirma-primeiro-caso-de-novo-coronavirus.

Negromonte, K. K. M. \& Silva, W. M. (2018). Uso de videoaulas na divulgação de conteúdos para o ensino e aprendizagem de língua portuguesa. Revista Letras Raras, 7 (1). http://revistas.ufcg.edu.br/ch/index.php/RLR/article/download/975/594.

Oliveira, A. \& Stadler, P. C. (2014). Videoaulas: uma forma de contextualizar a teoria na prática. Anais do $20^{\circ}$ Congresso Internacional ABED de Educação à Distância. www.abed.org.br/hotsite/20-ciaed/pt/anais/pdf/352.pdf.

Oliveira, S. J. \& Sugayama, S. (2014). Educação Física Escolar-Filmes como Recurso Didático. Cadernos PDE - Os Desafios da Escola Pública Paranaense na Perspectiva do Professor PDE, 1. http://www.diaadiaeducacao.pr.gov.br/portals/cadernospde/pdebusca/producoes_pde/201 4/2014_ufpr_edfis_artigo_sandro_jose_de_oliveira.pdf.

Pereira, F. D. F. \& Nascimento, G. P. (2017). O Ensino de Língua Portuguesa por meio de Memes. IV Simpósio Nacional de Linguagens e Gêneros Textuais. https://www.editorarealize.com.br/revistas/sinalge/trabalhos/TRABALHO_EV066_MD1_SA16_ID965_13032017153321.pdf. 
Research, Society and Development, v. 10, n. 2, e2431025498, 2021

(CC BY 4.0) | ISSN 2525-3409 | DOI: http://dx.doi.org/10.33448/rsd-v10i2.5498

Quintino, C. P. \& Ribeiro, K. D. F. (2010). A Utilização de filmes no processo de ensino aprendizagem de Química no Ensino Médio. XV Encontro Nacional de Ensino de Química. http://www.sbq.org.br/eneq/xv/resumos/R0472-1.pdf.

Rigo, J. R. V. (2014). Um olhar sobre o uso das TIC no ensino de Física. Dissertação de Mestrado. Centro Universitário Franciscano, 85p.

Rio de Janeiro. (2020). DECRETO No 46.973 DE 16 DE MARÇO DE 2020. Diário Oficial do Estado do Rio de Janeiro, 17 mar. 2020. http://estaticog1.globo.com/2020/03/17/17decreto.pdf?_ga=2.27791676.1616856722.1591122156-885883477.1568405999.

Santos, E. V. D. (2020). Reflexões sobre o uso das novas tecnologias como recurso didático no processo de ensino-aprendizagem. Educação Pública, 20 (13). https://educacaopublica.cecierj.edu.br/artigos/20/13/reflexoes-sobre-o-uso-das-novas-tecnologias-como-recurso-didatico-no-processo-de-ensino-eaprendizagem.

Schiehl, E. P., \& Gasparini, I. (2016). Contribuições do Google Sala de Aula para o Ensino Híbrido. Novas Tecnologias na Educação, 14 (2). https://seer.ufrgs.br/renote/article/download/70684/40120.

Silva, I. G. (2019). A utilização do meme no cotidiano e a sua aplicação em sala de aula. $14^{\circ}$ Encontro Nacional de Prática de Ensino de Geografia. https://ocs.ige.unicamp.br/ojs/anais14enpeg/article/download/3103/2966.

Souza, A. \& Souza, F. (2016). Uso da Plataforma Google Classroom como ferramenta de apoio ao processo de ensino e aprendizagem: Relato de aplicação no ensino médio. Monografia de Graduação. Universidade Federal da Paraíba, Centro de Ciências Aplicadas e Educação, 27p. 